ANNALS OF

APPLIED BIOLOGY

\title{
Investigation on 'bois noir' epidemiology in north-eastern Italian vineyards through a multidisciplinary approach
}

\begin{tabular}{|r|l|}
\hline Journal: & Annals of Applied Biology \\
\hline Manuscript ID: & AAB-2014-0067.R1 \\
\hline Manuscript Type: & Research paper \\
\hline Date Submitted by the Author: & n/a \\
\hline Complete List of Authors: & $\begin{array}{l}\text { Mori, Nicola; Università degli Studi di Padova, Dipartimento di Agronomia } \\
\text { Animali Alimenti Risorse Naturali e Ambiente } \\
\text { Quaglino, Fabio; Università degli Studi di Milano, Dipartimento di Scienze } \\
\text { Agrarie e Ambientali - Produzione, Territorio e Agroenergia } \\
\text { Tessari, Fabio; AGREA, Agrea Centro Studi } \\
\text { Pozzebon, Alberto; Università degli Studi di Padova, Dipartimento di } \\
\text { Agronomia Animali Alimenti Risorse Naturali e Ambiente } \\
\text { Bulgari, Daniela; Università degli Studi di Milano, Dipartimento di Scienze } \\
\text { Agrarie e Ambientali - Produzione, Territorio e Agroenergia } \\
\text { Casati, Paola; Università degli Studi di Milano, Dipartimento di Scienze } \\
\text { Agrarie e Ambientali - Produzione, Territorio e Agroenergia } \\
\text { Bianco, Piero; Università degli Studi di Milano, Dipartimento di Scienze } \\
\text { Agrarie e Ambientali - Produzione, Territorio e Agroenergia }\end{array}$ \\
\hline Key Words: & $\begin{array}{l}\text { grapevine yellows, host plants, Hyalesthes obsoletus, real-time PCR, } \\
\text { spatial analysis }\end{array}$ \\
\hline
\end{tabular}


1 Investigation on 'bois noir' epidemiology in north-eastern Italian 2 vineyards through a multidisciplinary approach

3

4 N. Mori ${ }^{1}$, F. Quaglino ${ }^{2}$, F. Tessari ${ }^{3}$, A. Pozzebon ${ }^{1}$, D. Bulgari ${ }^{2}$, P. Casati ${ }^{2}$, P.A. 5 Bianco $^{2}$

6

$7 \quad{ }^{1}$ Dipartimento di Agronomia Animali Alimenti Risorse Naturali e Ambiente, Università degli Studi di 8 Padova, Via dell'Università 16, 35020 Legnaro (PD), Italy

$9 \quad{ }^{2}$ Dipartimento di Scienze Agrarie e Ambientali - Produzione, Territorio e Agroenergia, Università degli Studi 10 di Milano, Via Celoria 2, 20133 Milan, Italy

$11{ }^{3}$ AGREA Centro Studi, Via Garibaldi 5, 37057 San Giovanni Lupatoto (VR), Italy 12

Running title: Bois noir epidemiology in North Italy

Correspondence: Piero A. Bianco, Dipartimento di Scienze Agrarie e Ambientali - Produzione, Territorio, Agroenergia, Università degli Studi di Milano, via Celoria 2, 20133 Milano, Italy. Tel : +39-02-50316794 ; fax : +39-02-50316781 ; e-mail: piero.bianco@unimi.it

(6)

.

(18)

$\begin{array}{ll}44 & 19 \\ 45 & \\ 46 & 20 \\ 47 & \\ 48 & 21 \\ 49 & \\ 50 & 22 \\ 51 & \\ 52 & 23 \\ 53 & \\ 54 & 24 \\ 55 & \\ 56 & 25 \\ 57 & \\ 58 & 26 \\ 59 & \\ 60 & \end{array}$




\section{Abstract}

2 A multidisciplinary approach, based on field surveys, molecular biology techniques, and spatial 3 data analyses, was utilized to investigate the Bois noir $(\mathrm{BN})$ epidemiology in north-eastern Italian

4 vineyards during the years 2010-2012. Symptomatic grapevines, weeds and specimens of the insect 5 vector Hyalesthes obsoletus were monitored and mapped. Leaf samples from symptomatic

6 grapevines and weeds, and captured insect specimens were analyzed by real-time PCR to identify 7 BN phytoplasma (BNp; 'Candidatus Phytoplasma solani' species), the etiological agent of BN. 8 Data spatial distribution was analyzed using SADIE (Spatial Analysis by Distance IndicEs). BNp 9 strains identified in weed candidates an epidemiological role were characterized by RFLP-based 10 characterization of tuf gene amplicons. Results highlighted that, in the examined areas, the host 11 systems Convolvulus arvensis - H. obsoletus and Urtica dioica - H. obsoletus play the main role in 12 BN diffusion. It was also evidenced that other weeds (i.e., Chenopodium album and Malva 13 sylvestris) spatially associated with symptomatic grapevines and/or insect vectors and infected by 14 the same tuf type identified in grapevines and insects, could play a role in $\mathrm{BN}$ diffusion. On the 15 other hand, some weeds (i.e., Trifolium repens) were uninfected and not associated with 16 symptomatic grapevines and/or insect vectors. The synergic application of our multidisciplinary 17 approach improved the knowledge of $\mathrm{BN}$ epidemiology, and provided helpful indication for 18 designing experimental plans to contain $\mathrm{BN}$ spreading in vineyards through weed management. The 19 approach described in the present work could be used to investigate the complex epidemiology of 20 other phytoplasma diseases.

Keywords: grapevine yellows; host plants; Hyalesthes obsoletus; real-time PCR; spatial analysis 


\section{Introduction}

2 Bois noir (BN), a grapevine yellows (GY) disease caused by 'Candidatus Phytoplasma solani' 3 strains [taxonomic 16SrXII ('stolbur') group, subgroup 16SrXII-A] (Wei et al., 2007; Quaglino et 4 al., 2013), is a major limiting factor for wine production in European countries (Laimer et al., 5 2009). In almost all varieties of Vitis vinifera L., BN produces typical GY symptoms, including 6 desiccation of inflorescences, berry shrivel, leaf discolorations, reduction of growth and irregular 7 ripening of wood (Belli et al., 2010). BN phytoplasma (BNp) strains are transmitted by the 8 planthopper Hyalesthes obsoletus Signoret (Homoptera: Cixiide), a polyphagous insect living 9 preferentially on weeds (Maixner, 1994; Langer \& Maixner, 2004; Berger et al., 2009). Up to now, three natural ecologies of BNp have been described: (1) the host system Convolvulus arvensis - H. obsoletus - Vitis vinifera, related to BNp strains of type tuf-b (2) the host system Urtica dioica - H. obsoletus - V. vinifera, related to type tuf-a and (3) the host system Calystegia sepium - H. obsoletus - V. vinifera, related to type tuf-c (Langer \& Maixner, 2004). In detail, C. arvensis and U. dioica have been reported as being the main host plants of H. obsoletus in Germany (Maixner et al., 1995), northern Italy (Alma et al., 2002; Lessio et al., 2007; Mori et al., 2008), Spain (Sabaté et al., 2014), and Austria (Riedle-Bauer et al., 2013). Alternative plant hosts of BNp include cultivated species as well as weeds found in or near vineyards (Marcone et al., 1997; Skoric et al., 1998; Batlle et al., 2000; Lessio et al., 2007; Borgo et al., 2008). In several areas, a correlation was noticed between the incidence of $\mathrm{BNp}$ in grapevines and in other plant species. This suggests a direct role of the other host plants in the epidemiology of BN disease (Borgo et al., 2008). Cardaria draba L., Prunus sp., Prunus domestica L., Syringa vulgaris L., Ficus carica L. and Ulmus sp. were shown to be susceptible to infection under experimental conditions; $C$. draba was identified as a favourable host plant for $H$. obsoletus (Sforza et al., 1998). Furthermore, in vine-growing areas where $H$. obsoletus is absent, the presence of BNp implies the existence of alternative vectors. Recently, Reptalus panzeri has been reported as a natural vector of BNp in Serbian vineyards (Cvrković et al., 2014). Anaceratagallia ribauti was also shown to carry the bindweed strain (type tuf-b) and to 
1 transmit it to some herbaceous hosts (Riedle-Bauer et al., 2008). In addition, other studies reported

2 that the Cixiidae Reptalus quinquecostatus, and the Cicadellidae Adarrus taurus, Aphrodes

3 bicinctus, Anaceratagallia laevis, Goniagnathus guttulinervis, Macrosteles sexnotatus, Neoaliturus

4 fenestratus, Psammotettix striatus and Zyginidia scutellaris have been captured within or near BN-

5 diseased vineyards and found to contain BNp (Batlle et al., 2000; Gatineau et al., 2001; Garau et

6 al., 2004; Palermo et al., 2004; Pinzauti et al., 2008). Based on such information, it appears that,

7 even if the role of these numerous hosts in BNp transmission has not been proven, it is probable that

8 other host plants are involved in the epidemiology of $\mathrm{BN}$ disease, harbouring additional insect

9 species capable of spreading the disease.

10 This complexity renders it difficult to design efficient BN control strategies. Insecticides

11 applied to the grapevine canopy influence neither the disease nor the presence of $H$. obsoletus

12 (Sforza \& Boudon-Padieu, 1998; Maixner, 2007; Mori et al., 2008). The management of $H$.

13 obsoletus host plants in the vineyards and surrounding areas is therefore considered crucial for BN

14 control. Indeed, in Europe, several studies showed that $H$. obsoletus host plants at the borders

15 facilitate the spread of BNp (Maixner et al., 2007; Riedle-Bauer, 2010; Mori et al., 2012). Thus,

16 preventive measures such as checking the sanitary status of propagation materials, and treating

17 diseased mother plants through thermotherapy are applied to limit long distance dissemination and

18 in-field spread of the disease (Belli et al., 2010). Other strategies for reducing BN spread or

19 incidence are based on (i) preventive removal of the grape suckers on which $H$. obsoletus could

20 feed after grass mowing (Picciau et al., 2010); (ii) trunk cutting above the engagement point on the

21 symptomatic grapevines (Credi et al., 2011); (iii) treatments by resistance inducers (Romanazzi et

22 al., 2009).

23 Recently, several researches have focused on improving the knowledge of BN epidemiology

24 in order to obtain information useful for developing efficient strategies of disease containment

25 (Marchi et al., 2011). Spatial Analysis by Distance IndicEs (SADIE) has been used to investigate

26 the epidemiology of ' $\mathrm{Ca}$. Phytoplasma solani' strains infecting tomato, pepper and celery in the 
1 Czech Republic, highlighting that distributions of symptomatic crop plants and of C. arvensis and

2 Cirsium arvense were associated, and suggesting the possible involvement of these weeds in the

3 spread of stolbur (Navratil et al., 2009). In the present study, we used a multidisciplinary approach

4 based on field surveys, molecular biology techniques and spatial data analyses to investigate the

5 role of weeds in $\mathrm{BN}$ epidemiology within vineyards in order to facilitate the development of novel

$6 \quad$ field strategies for controlling the spread of BNp.

\section{Materials and Methods}

9 The study was conducted in 2010-2011 and was based on (i) monitoring and mapping symptomatic 10 grapevines, weeds and $H$. obsoletus specimens for statistical analyses of data spatial distribution by 11 means of SADIE (Perry et al., 1999), (ii) identification of BNp through real-time PCR analyses 12 (Galetto et al., 2005) performed on leaf samples collected from symptomatic grapevines and weeds 13 and captured insect specimens. The monitoring and spatial distribution analysis of symptomatic 14 grapevines was also done in 2012.

\section{Characteristics of investigated vineyards}

The investigation on BN epidemiology was conducted in two vineyards (1.20 ha / 4995 vines - 1.32 ha / 4976 vines, respectively) of the Chardonnay cultivar on SO4 rootstock in a grape-growing area of the Veneto Region (Northern Italy) (N 45,302104' E 11,234721 ${ }^{\circ}$ Ronco all'Adige location; N 45.439782; E $11.140831^{\circ}$ San Pietro di Lavagno location). In both vineyards, rows were northsouth oriented and grapevines were trained using the Guyot system (distance between rows $2.8 \mathrm{~m}$ in both vineyards; plant distance along the row $0.9 \mathrm{~m}$ in Ronco all'Adige and $1.0 \mathrm{~m}$ in San Pietro di Lavagno). Among the agricultural practices adopted in the vineyards, spring weeding on the row, mowing between rows and one insecticide treatment with the organophosphate Chlorpyriphos ethyl (applied at the end of June / beginning of July) against insect pests should be mentioned because they could have interfered with vineyard colonization by H. obsoletus. 
The Ronco all'Adige vineyard is composed of 29 rows, $150 \mathrm{~m}$ long. It is bordered by a cereal field to the north, other vineyards to the south, an orchard to the east and a Platano acerifolia coppice to the west. The San Pietro di Lavagno vineyard is composed of 21 rows, $220 \mathrm{~m}$ long. It is bordered by buildings (houses and factories) to the north and east, other vineyards to the south and uncultivated meadows to the west.

\section{Spatial distribution}

A map was created of the vineyards and surrounding habitat, and the position of each grapevine plant was registered by a code comprising two numbers indicating the row and position on the row. In correspondence to each grapevine, the identified weed species were recorded to obtain a map of the flora present in the vineyards. In order to compare the spatial distribution of grapevines and weeds, the maps were referred to 200 block units in Ronco all'Adige ( $24 \pm 2$ plants per block; width 5.6m, length $10.8 \mathrm{~m} \pm 0.9 \mathrm{~m}$ ) and 225 block units in San Pietro di Lavagno (22 \pm 2 plants per block; width $5.6 \mathrm{~m}$, length $11.0 \mathrm{~m} \pm 1.0 \mathrm{~m})$. Each block was geo-tagged with GPS spatial coordinates.

Considering the mobility of H. obsoletus (Bressan et al., 2007; Mori et al., 2011), its distribution inside the vineyards was studied referring the adult captures within a regular grid. In order to compare the spatial distribution of grapevines, weeds and vector, the plant maps and insect grid were overlapped. In detail, the insect grid was referred to 25 block units in Ronco all'Adige (197 \pm 20 plants per block; width $15.4 \mathrm{~m} \pm 1.4 \mathrm{~m}$, length $32.5 \mathrm{~m} \pm 2.9 \mathrm{~m})$ and 24 block units in San Pietro di Lavagno $(210 \pm 23$ plants per block; width $15.4 \mathrm{~m} \pm 1.4 \mathrm{~m}$, length $38.5 \mathrm{~m} \pm 3.5 \mathrm{~m})$. Each block was geo-tagged with GPS spatial coordinates.

\section{Sampling of symptomatic grapevines}

The grapevines were classified as symptomatic or asymptomatic depending on the presence of BN symptoms (partial or total lack of lignification of canes and shoots, rolling of leaves, sectorial discolorations of the blades). The inspection was made each year by the same two people. They 
1 inspected both sides of the plants in order to accurately check the presence of BN symptoms and, at

2 the same time, exclude other causes of similar symptoms (e.g. partial broken canes, Stictocephala

3 bisonia Kopp and Yonke activity). From 2010 to 2012, the incidence of symptomatic grapevines

4 was evaluated in the vineyards. In 2011 and 2012, the incidence of new symptomatic grapevines

5 was calculated in comparison with the asymptomatic grapevines in the previous years. In each

6 block (used for insect grid) of both vineyards, five symptomatic leaves were collected from each of

7 two symptomatic grapevine plants for $\mathrm{BNp}$ identification through molecular analyses. More

8 precisely, in 2010-2011 leaf samples were collected from 96 grapevines in Ronco all'Adige and

9 from 100 grapevines in San Pietro di Lavagno. Collecting was done in September of each year, 10 when the BN symptoms are evident on diseased plants.

\section{Sampling of weeds}

As spontaneous grasses (monocotyledonous species, except Zea mays) are not reported as BNp host plants, investigations were exclusively on broadleaf species. In correspondence to each grapevine, the weed species observed at the two inter-row area sides were recorded and geo-tagged in order to obtain a map of the flora present in the vineyards. The incidence of each weed species was calculated as the percentage of grapevines (each vine was considered with its inter-row area sides) where the species was observed. In the middle of July, in each block used for the insect survey in both vineyards, five to ten leaves were collected from at least one plant of the more frequent weed species for BNp identification through molecular analyses. Given that no symptomatic weeds were present, weed plants were sampled randomly within each block. More precisely, in 2010-2011 leaf samples were collected from 231 weed plants in Ronco all'Adige and from 218 in San Pietro di Lavagno. Collecting was done in July of each year.

\section{Sampling of Hyalesthes obsoletus specimens}


1 In both vineyards, the presence of $H$. obsoletus was monitored every week from June to August by

2 using yellow sticky traps (SuperColor Giallo®, Serbios) placed in the center of each block unit. All

3 the H. obsoletus specimens captured (182 in Ronco all'Adige, and 283 in San Pietro di Lavagno)

$4 \quad$ were used for BNp identification through molecular analyses.

5

6

7

8

9

10

11

12

13

14

15

16

17

18

19

20

21

22

23

24

25

\section{BN phytoplasma identification}

In each block of both vineyards, leaves collected from symptomatic grapevine plants and from the more frequent weed species were prepared for DNA extraction. Central leaf veins and petioles of a total of five leaves per plant were dissected, chopped into 3-mm-long pieces, and mixed together. DNA was extracted from $1 \mathrm{~g}$ of prepared leaf tissues following the phytoplasma enrichment procedure as described by Angelini et al. (2001), with some modifications. Briefly, plant tissues were placed in plastic bags (Bioreba, France) and ground by a mechanical pestle in $4 \mathrm{ml}$ of CTAB (hexadecyl trimethyl-ammonium bromide)-based buffer plus ascorbic acid $0.5 \%$ pre-warmed to 60 ${ }^{\circ} \mathrm{C}$. Obtained homogenates $(800 \mu \mathrm{l})$ were transferred to $2 \mathrm{ml}$ tubes and held at $60{ }^{\circ} \mathrm{C}$ for $30 \mathrm{~min}$. After incubation, DNA was extracted with one volume of chloroform:iso-amylalcohol (24:1) and precipitated with one volume of isopropanol. Pellets were washed with $70 \%$ ethanol, air-dried, suspended in $400 \mu \mathrm{l}$ of TE $\mathrm{pH} 8.0$ buffer. DNAs were re-precipitated with 2 volumes of absolute ethanol and $10 \%$ volume of sodium acetate $3 \mathrm{M} \mathrm{pH} 5.2$. Pellets were washed with ethanol $70 \%$ and $80 \%$, air-dried, suspended in $100 \mu \mathrm{l}$ of $\mathrm{TE} \mathrm{pH} 8.0$ buffer, and maintained at $-30{ }^{\circ} \mathrm{C}$ until use.

Total genomic DNA was extracted from individual insects following a protocol adapted from Marzachì et al. (1998). Briefly, the ethanol-preserved adults were dried on filter paper and homogenized in CTAB-based buffer plus ascorbic acid $0.5 \%$. After incubation at $60{ }^{\circ} \mathrm{C}$ for 30 min, DNA was extracted with one volume of chloroform:isoamylalchool 24:1 v/v solution and then precipitated with the addition of one volume of cold isopropanol. The DNA pellet was then washed with $70 \%$ ethanol, vacuum dried and resuspended in $100 \mu 1 \mathrm{TE} \mathrm{pH} \mathrm{8.0.}$ 
Undiluted (insect) or 1:10 diluted (plants) extracted DNAs were used as templates $(1 \mu \mathrm{l})$ for

2

\section{Spatial Analysis by Distance IndicEs (SADIE)}

Data from vineyard monitoring, along with those from molecular identification of BNp in collected samples, were analyzed using the SADIE "red-blue plots" methodology to detect spatial patterns in symptomatic grapevines, weeds, $H$. obsoletus cumulative captures, and $\mathrm{BNp}$-infected $H$. obsoletus specimens within the season. This approach allows hypothesis testing for the presence of a spatial pattern in the form of clustering of a given variable into patches and gaps. SADIE red-blue identifies neighborhoods of consistently large or small counts by determining whether observed counts are arranged effectively at random or form clusters of similarly sized counts close to one another. The technique uses an algorithm to find the shortest distance to regularity within an observed matrix. SADIE calculates for each sampling point the dimensionless indexes of clustering $\left(\mathrm{v}_{\mathrm{i}} ; \mathrm{v}_{\mathrm{j}}\right)$ that measure the local contribution to patch (i.e., a group of relatively high-density counts close one to another) or to gap (i.e., a group of zero or relatively small counts close one to another). An overall test of clustering is then provided by the comparison of the mean value of $v_{i}$ and $v_{j}$ with their corresponding values generated under the null hypothesis of a random distribution $(\alpha=0.05)$ (Perry et al., 1999). Using linear kriging with 0 nugget variance kriging with SURFER (Golden Software Inc., CO), indexes of local aggregation $\left(\mathrm{v}_{\mathrm{i}} ; \mathrm{v}_{\mathrm{j}}\right)$ and catches were interpolated and mapped 
1 on a two-dimensional map showing their spatial distribution. Datasets produced in the red-blue 2 analysis are used to assess the similarity among spatial patterns detected for the different 3 components (symptomatic grapevines, weeds and $H$. obsoletus). Spatial association analyses in 4 SADIE package use a specific algorithm to determine the local spatial association and derive an 5 overall index of spatial association (X). Randomization test is used to calculate the significance 6 (Px) of the association index and to test the null hypothesis of no association (Perry \& Dixon, 7 2002). This is a two-tailed test that determines whether the clusters of the two species are associated $8(\mathrm{Px}<0.025)$, unassociated $(0.025<\mathrm{Px}<0.975)$ or dissociated $(\mathrm{P}<0.975)$. As grapevine plants 9 normally show BN symptoms from at least one year after the phytoplasma infection, spatial patterns 10 of new symptomatic grapevines (plants showing BN symptoms for the first time) were compared 11 with the spatial patterns of weeds and insects detected in the previous year (i.e., new symptomatic 12 grapevines 2011 vs weeds 2010).

13

BN phytoplasma typing

BN phytoplasmas, identified by real-time PCR in symptomatic grapevines, insect specimens and weeds spatially-associated with diseased grapevines and/or insects in at least one of the examined vineyards in 2010 and 2011, were typed by PCR-based amplifications of tuf gene, followed by restriction fragment length polymorphism (RFLP) analyses using the enzyme HpaII. PCR and RFLP reaction conditions were as previously described (Langer \& Maixner, 2004).

\section{Results}

\section{Distribution of symptomatic grapevines, weeds and $H$. obsoletus}

In the years 2010-2012, the incidence of symptomatic grapevines was stable in Ronco all'Adige and decreased in San Pietro di Lavagno (Table 1). Recovered plants were also observed in both vineyards in 2011-2012 (Table 1). Interestingly, the incidence of newly symptomatic grapevines (plants showing GY symptoms for the first time in the studied year) increased in Ronco all'Adige 
1 (35\% of overall symptomatic grapevines in 2011 and $41 \%$ in 2012$)$, and was stable (56\% of overall 2 symptomatic grapevines in 2011 and 2012) in San Pietro di Lavagno (Table 1).

3

Twenty-one (10 perennial and 11 annual) and 16 (9 perennial and 7 annual) weed species were identified in the Ronco all'Adige and San Pietro di Lavagno vineyards, respectively (Table 1), reflecting a typical vineyard ground cover of Veneto region (north-eastern Italy). In detail, 15 and 13 weed species were present in both years in the Ronco all'Adige and San Pietro di Lavagno vineyards, respectively. On the other hand, in the Ronco all'Adige vineyard, four weeds (Anagallis arvensis, Equisetum telmateia, Solanum nigrum and Erigeron canadensis) were observed only in 2010, and two (Plantago lanceolata and Veronica arvensis) only in 2011. In the San Pietro di Lavagno vineyard, Matricaria chamomilla, Erigeron canadensis and Portulaca oleracea were observed only in 2011. During the investigated period, seven and 10 weed species had an incidence $>50 \%$ in Ronco all'Adige and San Pietro di Lavagno, respectively (Table 1). The composition of weeds in the ground cover of the two vineyards was influenced by some agricultural practices such as irrigation, mowing and weeding.

Based on sticky trap captures, Hyalesthes obsoletus was found in almost all the vineyard blocks during the investigated period (Table 1). Its flight period was Jul 01 - Aug 12 in 2010 and Jul 09 - Aug 07 in 2011 in Ronco all'Adige vineyard; Jul 08 - Aug 19 in 2010 and Jul 07 - Aug 13 in 2011 in San Pietro di Lavagno vineyard. The number of H. obsoletus captured specimens was higher in 2010 (126 and 192 in Ronco all'Adige and San Pietro di Lavagno, respectively) than in 2011 (56 and 91 in Ronco all'Adige and San Pietro di Lavagno, respectively) (Table 1).

\section{BN phytoplasma identification}

SYBR ${ }^{\circledR}$ Green real-time PCR assay performed using 16SrXII-A subgroup-specific primer pair StolFw/StolRv amplified DNA from periwinkle plants infected by phytoplasma strain STOL (16SrXII-A), showing a Tm (Melting Temperature) of $81.5^{\circ} \mathrm{C}$, and a Ct (cross threshold) of 14 . No amplification was observed for periwinkle plants infected by phytoplasma strain SAY (16SrI-B) 
1 and reaction mixture devoid of DNA. Thus, only PCR products, amplified from grapevines, weeds

2 and insect specimens, showing a $\mathrm{Tm}$ of $81.5 \pm 0.2{ }^{\circ} \mathrm{C}$ and a $\mathrm{Ct}<37$ were associated with the 3 presence of BN phytoplasmas in analyzed plants and insects.

4

5

In the Ronco all'Adige vineyard, $96 \%$ and $98 \%$ of symptomatic grapevines analyzed were positive to real-time PCR amplification assays in 2010 and 2011, respectively (Table 2). In the San Pietro di Lavagno vineyard, $72 \%$ and $100 \%$ of symptomatic grapevines analyzed were positive to real-time PCR amplification assays in 2010 and 2011, respectively (Table 2).

BN phytoplasmas were identified in $3 \%$ and $22 \%$ of insects captured in the Ronco all'Adige vineyard in 2010 and 2011, respectively, and in 23\% of insects captured in the San Pietro di Lavagno vineyard in both 2010 and 2011 (Table 2).

In $2010-2011,11 \%$ and $21 \%$ of weed samples from Ronco all'Adige and San Pietro di Lavagno, respectively, were positive by real-time PCR. In detail, molecular analyses identified BN phytoplasmas (BNp) in seven and ten weed species at Ronco all'Adige and San Pietro di Lavagno, respectively. On the other hand, 13 and six weed species in Ronco all'Adige and San Pietro di Lavagno, respectively, were found to be uninfected (Table 3).

\section{SADIE analyses}

Spatial Analysis by Distance IndicEs detected significant clustering into patch/gap in the distributions of overall symptomatic grapevines and 12 weed species observed in Ronco all'Adige during 2010 (Table 4). During 2011, significant clustering into patch/gap was detected in the distribution of symptomatic grapevines and 12 weeds, while Plantago lanceolata and $H$. obsoletus BNp-infected specimens distribution was significantly clustered into gap only (Table 4). Moreover, distribution of grapevine plants showing yellows symptoms for the first time in 2011 was significantly clustered into patch (Table 4). In 2012, distribution of new symptomatic grapevines was significantly clustered into patch/gap (Table 4). 
SADIE evidenced that in 2010 spatial distributions of 10 weed species in San Pietro di

2 Lavagno were characterized by significant clustering into patch/gap, while clustering into gap only

3 was found in the distribution of Urtica dioica and H. obsoletus BNp-infected specimens (Table 5).

4 During 2011, distributions of 13 weed species were significantly clustered into patch/gap (Table 5).

5 Distribution of new symptomatic grapevines was significantly clustered into patch in 2011 and into

$6 \mathrm{patch} / \mathrm{gap}$ in 2012 (Table 5).

In the Ronco all'Adige vineyard in 2010, based on spatial association index (Table 6), distribution of overall symptomatic grapevines was found to be significantly associated with Urtica

9 dioica, Equisetum telmateia, Polygonum persicaria, Potentilla reptans and Rumex acetosa, and significantly dissociated from Lactuca serriola, Malva sylvestris and Portulaca oleracea. Distribution of captured and BNp-infected H. obsoletus specimens was associated with P. oleracea. In contrast, distribution of captured $H$. obsoletus specimens was found dissociated from $P$. persicaria. Distribution of new symptomatic grapevines observed in 2011 was associated with Veronica persica in 2010, and was dissociated from P. reptans and Sonchus oleraceus in 2010. In the same vineyard in 2011 (Table 6), distribution of overall symptomatic grapevines was associated with $U$. dioica. No associations were found between distributions of captured and BNp-infected insect specimens and weeds. The distribution of new symptomatic grapevines observed in 2012 was associated with M. sylvestris, V. persica and Amaranthus retroflexus in 2011, and dissociated from P. reptans in 2011 .

In San Pietro di Lavagno during 2010, the distribution of overall symptomatic grapevines was associated with five weeds (A. retroflexus, $U$. dioica, Convolvulus arvensis, $P$. reptans, and Plantago lanceolata) (Table 7). Moreover, distribution of captured H. obsoletus specimens was associated with $A$. retroflexus, $C$. arvensis, $M$. sylvestris, $R$. acetosa, and $P$. reptans; and it was dissociated from Artemisia vulgaris. Distribution of BNp-infected H. obsoletus specimens was associated with Chenopodium album, U. dioica, and P. reptans. Furthermore, distribution of new symptomatic grapevines observed in 2011 was associated with $U$. dioica and BNp-infected $H$. 
1 obsoletus specimens in 2010. In the same vineyard in 2011 (Table 7), distribution of overall

2 symptomatic grapevines was associated with $C$. arvensis, Trifolium pratense and Taraxacum

3 officinale; on the other hand, it was dissociated from C. album. No associations were found between

4 distributions of captured and BNp-infected insect specimens and weeds. Moreover, distribution of

5 new symptomatic grapevines observed in 2012 was associated with C. album, Matricaria

6 chamomilla, and Erigeron canadensis in 2011; and it was dissociated from six weeds (A. vulgaris,

7 C. arvensis, P. persicaria, P. oleracea, S. oleraceus and T. officinale) in 2011.

8

9

10

11

12

13

14

15

16

17

18

19

20

21

22

23

24

25

26

\section{BN phytoplasma typing}

Based on HpaII-RFLP profiles obtained from tuf gene amplicons, BNp types tuf-a and tuf-b were identified in the examined vineyards. In the Ronco all'Adige vineyard, BNp type tuf-a was identified in all grapevines (97 plants), H. obsoletus (16 specimens) and nettle (7 plants); on the other hand, BNp type tuf-b was identified in bindweed (6 plants) and C. album (4 plants) (data not shown). In the San Pietro di Lavagno vineyard, BNp type tuf-a was identified in grapevines (46 plants) and $H$. obsoletus (26 specimens); on the other hand, BNp type tuf-b was identified in grapevines (38 plants), H. obsoletus (37 specimens), bindweed (11plants), C. album (7 plants) and M. sylvestris (3 plants) (data not shown).

\section{Discussion}

Bois noir and other plant diseases associated with phytoplasmas have a complex biological cycle, involving different host plants and/or insect vectors. Due to a lack of knowledge about the epidemiology of such diseases, it is difficult to develop efficient strategies to manage their transmission (Weintraub \& Beanland, 2006). Recently, data spatial analysis was successfully used for an in-depth investigation on the possible role of host plants and insect vectors in the spread of phytoplasma diseases (Navratil et al., 2009; Bonnot et al., 2010; Rappussi et al., 2012). This approach can help to identify weed candidates whose role has to be determined by further research 
1 including phytoplasma detection and typing as well as investigating their link to potential vectors

2 and their role as host/reservoir plants. Thus, in this research, we used a multidisciplinary approach

3 to study the epidemiology of Bois noir disease, based on synergic application of field surveys, data

4 spatial analyses and molecular biology techniques on the three main components involved in $\mathrm{BN}$

5 diffusion in vineyards: grapevines (cultivated crop host), H. obsoletus (vector) and weeds (inoculum

6 source). phytoplasmas associated with GY diseases (i.e., Flavescence dorée, 'Ca. Phytoplasma vitis') (IRPCM, 2004; according to rule $28 \mathrm{~b}$ of the Bacteriological Code, ' $\mathrm{Ca}$. Phytoplasma vitis' is an incidental citation and does not constitute prior citation) have been reported, even in previous years

Molecular analyses revealed a high percentage of PCR-positive symptomatic grapevine samples, confirming the strong association between specific GY disease symptoms and infection by BNp ('Ca. Phytoplasma solani' strains) within the examined vineyards, where no other (Quaglino et al., 2009). On the other hand, the presence of PCR-negative symptomatic grapevines could be connected with the low titer and/or sporadic distribution of phytoplasmas in symptomatic plant tissues (Constable et al., 2003). The number of symptomatic grapevines was quite stable in Ronco all'Adige (around 9.5\% of the total) and in San Pietro di Lavagno (around 5\%) over the years, even if numerous newly symptomatic grapevines were observed in both vineyards in each year. Moreover, several recovered grapevines (symptomatic plants that spontaneously regain a healthy condition) (Osler et al., 1993; Belli et al., 2010) were reported. Interestingly, this evidence highlighted that the impact of $\mathrm{BN}$ on the examined vineyards and on the distribution of symptomatic grapevines is influenced by two main driving forces: (i) the transmission of BNp from infected source plant(s) to grapevines and (ii) the spontaneous recovery of diseased grapevines. These two components influenced the aggregation pattern of total symptomatic grapevines in the examined vineyards during the considered period, placing more epidemiological significance on the distribution of the new symptomatic plants. 
BNp-infection percentage (23\%) among captured H. obsoletus specimens, except for the Ronco all'Adige vineyard in 2010 (3\% BNp-infected insects), is in agreement with evidence from previous studies (Sforza et al., 1998; Bressan et al., 2007; Mori et al., 2008). Distribution of $H$. obsoletus, significantly clustered into patch/gap, was found to be associated only with new symptomatic grapevines and its weed hosts in 2010 in the San Pietro di Lavagno vineyard. This reinforces the idea that $H$. obsoletus is a BNp-vector (Gatineau et al., 2001; Palermo et al., 2004; Cvrković et al., 2014).

The results from PCR analyses showed that C. arvensis, U. dioica, P. persicaria, $T$. officinale, P. lanceolata, C. album, A. retroflexus, M. sylvestris, A. vulgaris and S. oleracea, previously reported as BNp-host plants (Langer \& Maixner, 2004; Berger et al., 2009; Kessler et al., 2011), were frequently infected by BNp. Furthermore, BNp was identified for the first time in E. canadensis, R. acetosa and P. oleracea. Interestingly, E. canadensis and P. oleracea were previously reported as host plants of ' $\mathrm{Ca}$. Phytoplasma pruni' and ' $\mathrm{Ca}$. Phytoplasma asteris' strains, respectively (Schneider et al., 1997). On the other hand, the species $A$. arvensis, $M$. chamomilla, $P$. reptans, S. nigrum, T. pratense, E. telmateia, L. serriola, $V$. arvensis and $V$. persica were found uninfected in the examined vineyards. In other studies performed in diverse geographic regions, $P$. reptans, S. nigrum and T. pratense were found as host plants of BNp (Batlle et al., 2000; Langer \& Maixner, 2004; Credi et al., 2006; Franova et al., 2009; Sabaté et al., 2014).

Based on BNp-positivity and statistically significant association with overall and/or new symptomatic grapevines and/or insect vector, we propose to rank the weeds identified in the examined vineyards in four epidemiological groups: weeds BNp-infected and associated with symptomatic grapevines and/or H. obsoletus captures in 2010 and 2011 in at least one of the studied vineyards (group 1); weeds $\mathrm{BNp}$-infected and associated with symptomatic grapevines and/or $H$. obsoletus captures in 2010 or 2011 in at least one of the studied vineyards (group 2); BNp-infected weeds, not associated with symptomatic grapevines and/or H. obsoletus captures, or uninfected but associated with symptomatic grapevines and/or H. obsoletus captures in 2010 or 2011 in at least one 
1 of the studied vineyards (group 3); uninfected weeds and not associated with symptomatic 2 grapevines and/or H. obsoletus captures (group 4).

3 Based on this epidemiological classification, group 1 includes C. arvensis and U. dioica, 4 widely reported as $\mathrm{BNp}$ and $H$. obsoletus host plants involved in the $\mathrm{BN}$ epidemiology throughout 5 Europe (Johannesen et al., 2012), C. album and M. sylvestris; group 2 includes A. retroflexus and $P$. 6 lanceolata; group 3 includes A. vulgaris, E. telmateia, E. canadensis, M. chamomilla, P. major, P. 7 persicaria, P. oleracea, P. reptans, S. oleraceus, R. acetosa, T. officinale, T. pratense and $V$. 8 persica; group 4 includes $A$. arvensis, L. serriola, S. nigrum, T. repens and V. arvensis. 2010 and 2011 in the Ronco all'Adige vineyard and only in 2010 in the San Pietro di Lavagno

Within group 1, U. dioica showed association with symptomatic grapevines and insects in vineyard (Fig. 1). On the other hand, C. album, C. arvensis and M. sylvestris showed association with symptomatic grapevines and H. obsoletus in 2010 and 2011 only in the San Pietro di Lavagno vineyard. Interestingly, association of such weeds with symptomatic grapevines and insects significantly clustered into patch/gap indicated the strict relationships among these different epidemiological components. In order to validate the combined data from spatial analyses and BNp detection, suggesting that plant species of epidemiological group 1 (U. dioica, C. arvensis, $C$. album and M. sylvestris) are weed candidates as BNp inoculum source and could play a role in its transmission, tuf gene typing was carried out on BNp strains identified in grapevines, $H$. obsoletus, and these weeds. In the Ronco all'Adige vineyard, where nettle, bindweed and C. album were found BNp-infected, but only the distribution of nettle was associated with symptomatic grapevines, BNp type tuf-a was detected in nettles and in all grapevines and $H$. obsoletus specimens analyzed. In the same vineyard, bindweed and C. album were infected by BNp type tuf-B. Distribution and prevalence of BNp tuf types in the analyzed hosts confirmed that only nettle (BNp type tuf-a), spatially associated with diseased grapevines and infected by the same BNp tuf type (tuf-a) identified in grapevines and vector specimens, play a role in the diffusion of $\mathrm{BNp}$ in the Ronco all'Adige vineyard. Moreover, in the same vineyard, the scarce presence of BNp-infected $H$. 
1 obsoletus and its distribution not associated with nettle suggested the possibility that additional

2 vector(s) of the BNp type tuf-a could be present. Additionally, in the San Pietro di Lavagno

3 vineyard, where bindweed, C. album and M. sylvestris were found infected by BNp type tuf-b and

4 spatially associated with symptomatic grapevines and $H$. obsoletus, both BNp types tuf-a and tuf-b

5 were identified in symptomatic grapevines and in insect vector specimens. The spatial analysis and

6 the co-presence of BNp type tuf-b in grapevines, insects and weeds highlighted the role of

7 bindweed, C. album and M. sylvestris as potential inoculum source of BNp. On the other hand,

8 identification of BNp type tuf-a in grapevines and insects and their spatial association with nettle

9 (reported as exclusive weed host of BNp type tuf-a) suggested that nettle, even present in low 10 density (only two plants randomly collected were uninfected), play a role in BNp type tuf-a

11 transmission in this vineyard. Such evidence, obtained by comparing data of spatial and molecular 12 analyses (identification and typing of $\mathrm{BNp}$ ), revealed that SADIE spatial analyses provided a strong 13 indication on determining the role of weed candidates as inoculum source of BNp.

14 Association of $U$. dioica and $C$. arvensis with symptomatic grapevines and insect vector 15 captures, and their different distribution clustering within the examined vineyards are fully in

agreement with the results reported in previous studies on BN epidemiology in Europe (Sforza et al., 1999; Maixner et al., 2007; Kessler et al., 2011; Mori et al., 2012). On the other hand, further studies should be carried out to confirm the role of C. album and M. sylvestris in BN diffusion. In particular, additional research should be performed to investigate the association of the perennial species M. sylvestris with the larval stage of $H$. obsoletus and with other vector(s). Moreover, considering that perennial plants are the main phytoplasma reservoirs and hosts of the vectors (Weintraub \& Beanland, 2006), it is interesting to report the presence of one annual weed ( $C$. album) within this group 1. This could be explained by different hypotheses. Firstly, this weed could favor the BNp diffusion over the years by means of seeds, as reported for other annual plants (Olivier et al., 2010; Calari et al., 2011). Secondly, some infections in the weed flora might result from alternative epidemiological cycles with alternative vectors and with or without relation to 
1 grapevines. H. obsoletus becomes infected during its larval stage (Maixner, 2011). As its larval

2 development is not possible on C. album because it is an annual species, H. obsoletus cannot 3 acquire BN phytoplasma from this weed. Considering the six weeks activity period of adult $H$.

4 obsoletus observed in the present study, feeding of infective adult vectors on C. album could

5 explain the occurrence of infected plants. On the other hand, C. album could constitute the

6 inoculation target and the acquisition source of alternative vector(s), probably present in the

7 vineyard as adults for a longer period, during the same vegetative season.

Within group 2, A. retroflexus and $P$. lanceolata were associated with symptomatic 9 grapevines significantly clustered into patch/gap only in 2010, indicating a temporally limited strict relationship among the different epidemiological components. Within group 3, BNp-infected weeds, not associated with symptomatic grapevines and/or vector captures in the same vineyard, were $A$. vulgaris, $P$. major, $P$. persicaria, $P$. oleracea and $S$. arvensis; uninfected weeds associated with symptomatic grapevines and/or vector captures were E. telmateia, M. chamomilla, P. reptans, $T$. pretense and $V$. persica. Based on this evidence, all the weeds of epidemiological groups 2 and 3 have no clear role in spreading the $\mathrm{BN}$ in the examined vineyards, but given their $\mathrm{BNp}$-infection or associations and data from previous studies they could have a role in $\mathrm{BN}$ diffusion. For example, $A$. vulgaris was reported as host plant of $H$. obsoletus (Alma et al., 1988) and P. reptans was found as host plant of BNp (Credi et al., 2006).

Weeds belonging to group 4 do not play a role in BN epidemiology because of their scarce ground cover, except for T. repens (Fig. 2), and the absence of phytoplasma infection and associations.

Data obtained in this and previous studies indicate that BN epidemiology is influenced by several weed species and their distribution patterns inside and outside vineyards (Maixner et al., 2007, 2013), and could provide helpful indications for designing experimental plans to contain BN spreading in vineyards through weed management (Riedle-Bauer et al., 2010). Given that BNpinfected and associated weeds are dicotyledonous, it could be important to favor the vineyard 
1 ground cover with grass instead of broadleaves by sowing selected grass species at transplanting,

2 applying selective chemical treatments and frequent cutting. In conclusion, this work highlighted

3 that in the examined areas (i) the host systems C. arvensis - H. obsoletus and U. dioica - H.

4 obsoletus have a role in BN diffusion; (ii) other weeds could play a role in BN diffusion; (iii) new

5 wild plants have been found as BNp hosts; (iv) the synergic application of multidisciplinary

6 methods improved the knowledge of BN epidemiology. As pedo-climatic conditions and

7 agricultural practices influence the vineyard ecosystems, further studies should be conducted in

8 different grape-growing areas over more years to investigate BN epidemiology more accurately. In

9 particular, the role of additional potential vectors, suggested here by the association of some weeds

10 with symptomatic grapevines but not with $H$. obsoletus, and the genotyping of BNp strains

11 infecting symptomatic grapevines, insects and weeds should be considered. Furthermore, the

12 experimental approach used in the present study could be a suitable tool for obtaining accurate

13 information about the epidemiology of other diseases associated with phytoplasmas characterized

14 by complex ecological cycles.

15

16

17

18

19

\section{Acknowledgements}

This research was funded by the Veneto Region within the project "Prevenzione e contenimento del Legno nero della vite nella Regione Veneto”, 2008-2011. We would like to thank Drs Anna Zorloni (University of Milan), Alessandro Motta and Matteo Brigatti (University of Turin) for their technical assistance during field trials and laboratory analyses.

\section{References}

1. Alma A., Arnò C., Arzone A., Vidano C. (1988) New biological reports on Auchenorrhyncha in vineyards. In Proceedings of $6^{\text {th }}$ Auchenorrhyncha Meeting, Turin 1987, pp 509-516. Eds. Vidano C. and Arzone A., Italy. 
2. Alma A., Soldi G., Tedeschi R., Marzachì C. (2002) Ruolo di Hyalesthes obsoletus Signoret (Homoptera, Cixiidae) nella trasmissione del legno nero della vite in Italia. Petria, 12, $411-412$.

7. Bonnot F., de Franqueville H., Lourenço E. (2010) Spatial and spatiotemporal pattern analysis of coconut lethal yellowing in Mozambique. Phytopathology, 100, 300-312.

8. Borgo M., Albanese G., Quaglino F., Casati P., Ermacora P., Ferretti L., Ferrini F., Filippin L., Pasquini G., Angelini E. (2008) Ruolo di altre piante nell'epidemiologia dei fitoplasmi agenti di Flavescenza dorata e Legno nero. Petria, 18, 261-263.

9. Bressan A., Turata R., Maixner M., Spiazzi S., Boudon-Padieu E., Girolami V. (2007) Vector activity of Hyalesthes obsoletus living on nettles and transmitting a stolbur phytoplasma to grapevines: a case study. Annals of Applied Biology, 150, 331-339.

10. Calari A., Paltrinieri S., Contaldo N., Sakalieva D., Mori N., Duduk B., Bertaccini A. (2011) Molecular evidence of phytoplasmas in winter oilseed rape, tomato and corn seedlings. Bulletin of Insectology, 64, S157-S158. 
11. Constable F.E., Gibb K.S., Symons R.H. (2003) Seasonal distribution of phytoplasmas in Australian grapevines. Plant Pathology, 52, 267-276.

12. Credi R., Terlizzi F., Milanesi L., Bondavalli R., Cavallini G., Montermini A., Dradi D. (2006) Wild host plants of stolbur phytoplasma and its vector, Hyalesthes obsoletus, at sites of grapevine Bois noir occurrence in Emilia-Romagna, Italy. In Extended Abstracts $15^{\text {th }}$ Meeting ICVG, Stellenbosch, South Africa, pp 182-184.

13. Credi R., Terlizzi F., Reggiani N., Bacchiavini M. (2011) Vines healed from black wood with topping. Informatore Agrario, 67, 60-63.

14. Cvrković T., Jović J., Mitrović M., Krstić O., Toševski I. (2014) Experimental and molecular evidence of Reptalus panzeri as a natural vector of bois noir. Plant Pathology, 63, 42-53.

15. Franova J., Navratil M., Jakesova H. (2009) Molecular identification of stolbur phytoplasma associated with red clover dwarf disease symptoms. Journal of Phytopathology, 157, 52-56.

16. Galetto L., Bosco D., Marzachì C. (2005) Universal and group-specific real-time PCR diagnosis of flavescence dorée $(16 \mathrm{Sr}-\mathrm{V})$, bois noir (16Sr-XII) and apple proliferation (16SrX) phytoplasmas from field-collected plant hosts and insect vectors. Annals of Applied Biology, 147, 191-201.

17. Garau R., Sechi A., Tolu G., Prota V.A., Lentini A., Prota U. (2004) Goniagnathus guttulinervis (Kirschbaum), new natural host of the Stolbur subgroup 16SrXII-A phytoplasmas in Sardinia. Journal of Plant Pathology, 86, 179.

18. Gatineau F., Larrue J., Clair D., Lorton F., Richard-Molard M., Boudon-Padieu E. (2001) A new natural planthopper vector of stolbur phytoplasma in the genus Pentastiridius (Hemiptera : Cixiidae). European Journal of Plant Pathology, 107, 263-271.

19. IRPCM Phytoplasma/Spiroplasma Working Team - Phytoplasma Taxonomy Group (2004) 'Candidatus Phytoplasma', a taxon for the wall-less, non-helical prokaryotes that colonize 
plant phloem and insects. International Journal of Systematic and Evolutionary Microbiology, 54, 1243-1255.

20. Johannesen J., Foissac X., Kehrli P., Maixner M. (2012) Impact of vector dispersal and hostplant fidelity on the dissemination of an emerging plant pathogen. PLOS ONE, 7:e51809.

21. Kessler S., Schaerer S., Delabays N., Turlings T.C.J., Trivellone V., Kehrli P. (2011) Host plant preferences of Hyalesthes obsoletus, the vector of the grapevine yellows disease "bois noir', in Switzerland. Entomologia Experimentalis et Applicata, 139, 60-67.

22. Laimer M., Lemaire O., Herrbach E., Goldschmidt V., Minafra A., Bianco P., Wetzel T. (2009) Resistance to viruses, phytoplasmas and their vectors in the grapevine in Europe: a review. Journal of Plant Pathology, 91, 7-23.

23. Langer M., Maixner M. (2004) Molecular characterisation of grapevine yellows associated phytoplasmas of the stolbur-group based on RFLP-analysis of non-ribosomal DNA. Vitis, 43, 191-200.

24. Lessio F., Tedeschi R., Alma A. (2007) Population dynamics, host plants and infection rate with stolbur phytoplasma of Hyalesthes obsoletus Signoret in North-Western Italy. Journal of Plant Pathology, 89, 97-102.

25. Maixner M. (1994) Transmission of German grapevine yellows (Vergilbungskrankheit) by the planthopper Hyalesthes obsoletus (Auchenorrhyncha: Cixiidae). Vitis, 33, 103-104.

26. Maixner M. (2007) Biology of Hyalesthes obsoletus and approaches to control this soilborne vector of Bois noir disease. Bulletin OILB/SROP, 30, 3-9.

27. Maixner M. (2011). Recent advances in Bois noir research. Petria, 21, 17-32.

28. Maixner M., Ahrens U., Seemüller E. (1995) Detection of the grapevine yellows MLO in grapevine, alternative hosts and a vector by a specific PCR procedure. European Journal of Plant Pathology, 101, 241-250. 
29. Maixner M., Johannesen J. (2013). The spatiotemporal distribution of Hyalesthes obsoletus, nettle host plants and stolbur phytoplasma in a fallow vineyard. In Proceedings of the $3^{\text {rd }}$ European Bois Noir Workshop, pp 37-39. Eds. Torres E., Laviña A., and Batlle A., Spain.

30. Maixner M., Johannesen J., Michel K., Lux B., Seitz A. (2007) Host plant specificity of Hyalesthes obsoletus and consequences for "bois noir" epidemiology. Bulletin of Insectology, 60, 399-400.

31. Marchi G., Contaldo N., Braccini P., Paltrinieri S., Rizzo D., Cinelli T., Bertaccini A. (2011) Spread of BN in organic vineyards in Tuscany: spatial pattern analysis and identification of the phytoplasma in weeds. Bulletin of Insectology, 64, S193-S194.

32. Marcone C., Ragozzino A., Seemüller E. (1997) Detection and identification of phytoplasmas in yellows-diseased weeds in Italy. Plant Pathology, 46, 530-537.

33. Marzachì C., Veratti F., Bosco D. (1998) Direct PCR detection of phytoplasmas in experimentally infected insects. Annals of Applied Biology, 133, 45-54.

34. Mori N., Pavan F., Bondavalli R., Reggiani N., Paltrinieri S., Bertaccini A. (2008) Factors affecting the spread of "Bois Noir" disease in north Italy vineyards. Vitis, 47, 65-72.

35. Mori N., Pavan F., Reggiani N., Bacchiavini M., Mazzon L., Paltrinieri S., Bertaccini A. (2012) Correlation of bois noir disease with nettle and vector abundance in northern Italy vineyards. Journal of Pest Science, 85, 23-28.

36. Mori N., Reggiani N., Pozzebon A., Duso C., Pavan F. (2011) Influence of nettle control along a ditch on spatial distribution of Hyalesthes obsoletus Signoret in a neighbouring vineyard. IOBC/WPRS Bulletin, 67, 295-298.

37. Navratil M., Valova P., Fialova R., Lauterer P., Safarova D., Stary M. (2009) The incidence of stolbur disease and associated yield losses in vegetable crops in South Moravia (Czech Republic). Crop Protection, 28, 898-904. 
38. Olivier C.Y., Galka B., Seguin-Swartz G. (2010) Detection of aster yellows phytoplasma

2

3 DNA in seed and seedlings of canola (Brassica napus and B. rapa) and AY strain identification. Canadian Journal of Plant Pathology, 32, 298-305.

39. Osler R., Carraro L., Loi N., Refatti E. (1993) Symptom expression and disease occurrence of a Yellows disease of grapevine in Northeastern Italy. Plant Disease, 77, 496-498.

40. Palermo S., Elekes M., Botti S., Ember I., Alma A., Orosz A., Bertaccini A., Kölber M. (2004) Presence of Stolbur phytoplasma in Cixiidae in Hungarian vineyards. Vitis, 43, 201-203.

41. Perry J.N., Dixon P.M. (2002) A new method to measure spatial association for ecological count data. Ecoscience, 9, 133-141.

42. Perry J.N., Winder L., Holland J.M., Alston R.D. (1999) Red-blue plots for detecting clusters in count data. Ecology Letters, 2, 106-113.

43. Picciau L., Lavezzaro S., Morando A., Cesano A., Cuttini D., Saladini M.A., Alma A. (2010) Controlling the vector limits the black wood incidence in grapevines. Informatore Agrario, 25, 57-59.

44. Pinzauti F., Trivellone V., Bagnoli B. (2008) Ability of Reptalus quinquecostatus (Hemiptera: Cixiidae) to inoculate stolbur phytoplasma to artificial feeding medium. Annals of Applied Biology, 153, 299-305.

45. Quaglino F., Mori N., Casati P., Zorloni A., Zanini G., Bianco P.A. (2009) Further data on occurrence of grapevine yellows-associated phytoplasmas in vineyards of Veneto region (north-eastern Italy). Progrès Agricole et Viticole, Horse Série, 204-205.

46. Quaglino F., Zhao Y., Casati P., Bulgari D., Bianco P.A., Wei W., Davis R.E. (2013) 'Candidatus Phytoplasma solani', a novel taxon associated with stolbur and bois noir related diseases of plants. International Journal of Systematic and Evolutionary Microbiology, 63, 2879-2894. 
47. Rappussi M.C.C., Eckstein B., Flôres D., Haas I.C.R., Amorim L., Bedendo I.P. (2012) Cauliflower stunt associated with a phytoplasma of subgroup 16SrIII-J and the spatial pattern of disease. European Journal of Plant Pathology, 133, 829-840.

48. Riedle-Bauer M. (2010) Stolbur phytoplasma (black wood disease) of grape: Current knowledge and new research results. Mitteilungen Klosterneuburg, 60, 69-73.

49. Riedle-Bauer M., Hanak K., Sára A., Bauer H. (2010). Control of Bois noir and practices increasing biodiversity- a contradiction? Mitteilungen Klosterneuburg, 60, 376-381.

50. Riedle-Bauer M., Mörtel J., Pastar M., Aryan A., Brader G. (2013). Mass occurrence of Hyalesthes obsoletus on Urtica dioica in Austria and sole presence of tuf-type b stolbur phytoplasma on stinging nettles, grapevine and in the transmitting insects. In Proceedings of the 3er European Bois Noir Workshop, Barcelona 2013, pp 26-27. Eds. Torres E., Laviña A. and Batlle A., Spain.

51. Riedle-Bauer M., Sára A., Regner F. (2008). Transmission of a stolbur phytoplasma by the Agalliinae leafhopper Anaceratagallia ribauti (Hemiptera, Auchenorrhyncha, Cicadellidae). Journal of Phytopathology, 156, 687-690.

52. Romanazzi G., D'Ascenzo D., Murolo S. (2009) Field treatment with resistance inducers for the control of grapevine bois noir. Journal of Plant Pathology, 91, 677-682.

53. Sabaté J., Laviña A., Batlle A. (2014) Incidence of Bois Noir phytoplasma in different viticulture regions of Spain and Stolbur isolates distribution in plants and vectors. European Journal of Plant Pathology, 139, 185-193

54. Schneider B., Marcone C., Kampmann M., Ragozzino A., Lederer W., Cousin M.T., Seemüller E. (1997) Characterization and classification of phytoplasmas from wild and cultivated plants by RFLP and sequence analysis of ribosomal DNA. European Journal of Plant Pathology, 103, 675-686.

55. Sforza R., Boudon-Padieu E. (1998) The main vector of bois noir disease. Phytoma, 510, $33-37$. 
1 56. Sforza R., Bourgoin T., Wilson S.W., Boudon-Padieu E. (1999) Field observations, 2 laboratory rearing and descriptions of immatures of the planthopper Hyalesthes obsoletus

3 (Hemiptera : Cixiidae). European Journal of Entomology, 96, 409-418. Journal of Phytopathology, 146, 549-556.

58. Skoric D., Saric A., Vibio M., Murari E., Krajacic M., Bertaccini A. (1998) Molecular identification and seasonal monitoring of phytoplasmas infecting Croatian grapevines. Vitis, 37, 171-175.

59. Wei W., Davis R.E., Lee I.-M., Zhao Y. (2007) Computer-simulated RFLP analysis of 16S rRNA genes: identification of ten new phytoplasma groups. International Journal of Systematic and Evolutionary Microbiology. 57, 1855-1867.

60. Weintraub P.G., Beanland L. (2006) Insect vectors of phytoplasmas. Annual Review of Entomology, 51, 91-111. 
Mori et al., Annals of Applied Biology

1

2

Table 1 Incidence of symptomatic and recovered grapevines, insects and weeds

\begin{tabular}{|c|c|c|c|c|c|c|}
\hline & \multicolumn{6}{|c|}{ Incidence } \\
\hline & \multicolumn{3}{|c|}{ Ronco all'Adige } & \multicolumn{3}{|c|}{ S. Pietro di Lavagno } \\
\hline & 2010 & 2011 & 2012 & 2010 & 2011 & 2012 \\
\hline \multicolumn{7}{|l|}{ Grapevines } \\
\hline Overall symptomatic grapevines & 9.2 & 9.8 & 9.3 & 5.8 & 3.4 & 4.7 \\
\hline New symptomatic grapevines & & 3.5 & 3.9 & & 1.9 & 2.6 \\
\hline Recovered symptomatic grapevines & & 0.4 & 1.0 & & 0.8 & 3.5 \\
\hline \multicolumn{7}{|l|}{ Insects } \\
\hline Hyalesthes obsoletus Signoret ${ }^{\mathrm{a}}$ & 126 & 56 & & 192 & 91 & \\
\hline \multicolumn{7}{|l|}{ Weeds } \\
\hline Amaranthus retroflexus L. & 52.0 & 40.0 & & 83.3 & 66.7 & \\
\hline Anagallis arvensis $\mathrm{L}$. & 24.0 & & & & & \\
\hline Artemisia vulgaris $\mathrm{L}$. & & & & 95.8 & 79.2 & \\
\hline Chenopodium album $\mathrm{L}$. & 64.0 & 88.0 & & 100.0 & 45.8 & \\
\hline Convolvolus arvensis $\mathrm{L}$. & 100.0 & 100.0 & & 100.0 & 75.0 & \\
\hline Equisetum telmateia Ehrh. & 8.0 & & & & & \\
\hline Erigeron canadensis L. & 56.0 & & & & 100.0 & \\
\hline Lactuca serriola $\mathrm{L}$. & 44.0 & 20.0 & & & & \\
\hline Malva sylvetsris $\mathrm{L}$. & 4.0 & 4.0 & & 79.2 & 83.3 & \\
\hline Matricaria chamomilla $\mathrm{L}$. & & & & & 8.3 & \\
\hline Plantago lanceolata $\mathrm{L}$. & & 52.0 & & 100.0 & 83.3 & \\
\hline Plantago major L. & 100.0 & 100.0 & & & & \\
\hline Polygonum persicaria $\mathrm{L}$. & 16.0 & 36.0 & & 95.8 & 95.8 & \\
\hline Portulaca oleracea $\mathrm{L}$. & 20.0 & 100.0 & & & 50.0 & \\
\hline Potentilla reptans $\mathrm{L}$. & 12.0 & 16.0 & & 20.8 & 20.8 & \\
\hline Rumex acetosa L. & 32.0 & 72.0 & & 79.2 & 87.5 & \\
\hline Solanum nigrum $\mathrm{L}$. & 20.0 & & & & & \\
\hline Sonchus oleraceus L. & 100.0 & 56.0 & & 95.8 & 87.5 & \\
\hline Trifolium pratense $\mathrm{L}$. & & & & 100.0 & 75.0 & \\
\hline Trifolium repens $\mathrm{L}$. & 96.0 & 100.0 & & & & \\
\hline Taraxacum officinale (L.) Wiggers & 100.0 & 100.0 & & 83.3 & 83.3 & \\
\hline Urtica dioica $\mathrm{L}$. & 68.0 & 68.0 & & 12.5 & 8.3 & \\
\hline Veronica arvensis $\mathrm{L}$. & & 44.0 & & & & \\
\hline Veronica persica Poir. & 36.0 & 68.0 & & & & \\
\hline
\end{tabular}


1 Table 2 BN phytoplasma identification in grapevine samples and Hyalesthes obsoletus specimens

Table 3 BN phytoplasmas identification in collected weeds

\begin{tabular}{|c|c|c|}
\hline \multirow[t]{2}{*}{ Species } & \multicolumn{2}{|c|}{ Infected / Collected } \\
\hline & Ronco all'Adige & San Pietro di Lavagno \\
\hline Amaranthus retroflexus $\mathrm{L}$. & $0 / 3$ & $6 / 19$ \\
\hline Anagallis arvensis $\mathrm{L}$. & $0 / 3$ & \\
\hline Artemisia vulgaris $\mathrm{L}$. & - & $5 / 20$ \\
\hline Chenopodium album $\mathrm{L}$. & $4 / 11$ & $7 / 23$ \\
\hline Convolvulus arvensis $\mathrm{L}$. & $6 / 41$ & $11 / 31$ \\
\hline Erigeron canadensis $\mathrm{L}$. & $2 / 9$ & - \\
\hline Equisetum telmateia Ehrh. & $0 / 1$ & - \\
\hline Lactuca serriola $\mathrm{L}$. & $0 / 3$ & - \\
\hline Malva sylvestris $\mathrm{L}$. & - & $3 / 10$ \\
\hline Matricaria chamomilla $\mathrm{L}$. & & $0 / 4$ \\
\hline Plantago major $\mathrm{L}$. & $2 / 20$ & - \\
\hline Plantago lanceolata $\mathrm{L}$. & - & $3 / 16$ \\
\hline Polygonum persicaria $\mathrm{L}$. & $0 / 2$ & $7 / 23$ \\
\hline Portulaca oleracea L. & $0 / 3$ & $1 / 5$ \\
\hline Potentilla reptans $\mathrm{L}$. & $0 / 1$ & $0 / 3$ \\
\hline Rumex acetosa $\mathrm{L}$. & $0 / 1$ & $3 / 9$ \\
\hline Solanum nigrum $\mathrm{L}$. & $0 / 2$ & \\
\hline Sonchus oleraceus L. & $2 / 28$ & $1 / 20$ \\
\hline Taraxacum officinale (L.) Wiggers & $4 / 26$ & $0 / 19$ \\
\hline Trifolium pratense $\mathrm{L}$ & - & $0 / 13$ \\
\hline Trifolium repens $\mathrm{L}$. & $0 / 7$ & - \\
\hline Urtica dioica $\mathrm{L}$. & $7 / 64$ & $0 / 2$ \\
\hline Veronica arvensis $\mathrm{L}$. & $0 / 3$ & \\
\hline Veronica persica Poir. & $0 / 2$ & - \\
\hline
\end{tabular}

\begin{tabular}{|c|c|c|c|c|c|}
\hline \multirow[b]{2}{*}{ Vineyard } & \multirow[b]{2}{*}{ Host } & \multicolumn{2}{|l|}{2010} & \multicolumn{2}{|l|}{2011} \\
\hline & & infected / analyzed & $\%$ infection & infected / analyzed & $\%$ infection \\
\hline \multirow[t]{2}{*}{ Ronco all'Adige } & grapevine & $48 / 50$ & 96 & $49 / 50$ & 98 \\
\hline & H. obsoletus & $4 / 126$ & 3 & $12 / 56$ & 22 \\
\hline \multirow[t]{2}{*}{ San Pietro di Lavagno } & grapevine & $36 / 48$ & 72 & $48 / 48$ & 100 \\
\hline & H. obsoletus & $44 / 192$ & 23 & $21 / 91$ & 23 \\
\hline
\end{tabular}

2

3

4 
1 Table 4 Average indexes of clustering into patch (mean $\mathrm{v}_{\mathrm{i}}$ ) and into gap (mean $\mathrm{v}_{\mathrm{j}}$ with associated probability (P) from randomization test in Ronco 2 all'Adige vineyard

\begin{tabular}{|c|c|c|c|c|c|c|c|c|}
\hline \multirow[t]{2}{*}{ Folder } & \multicolumn{4}{|c|}{2010} & \multicolumn{4}{|c|}{2011} \\
\hline & mean $v_{i}$ & $P\left(\right.$ mean $\left.v_{i}\right)$ & mean $\mathbf{v}_{\mathbf{j}}$ & $P\left(\right.$ mean $\left.v_{j}\right)$ & $\operatorname{mean} v_{i}$ & $P\left(\right.$ mean $\left.v_{i}\right)$ & mean $\mathbf{v}_{\mathbf{j}}$ & $P\left(\right.$ mean $\left.v_{j}\right)$ \\
\hline Overall symptomatic grapevines & 1.652 & 0.0085 & -1.796 & 0.0085 & 1.59 & 0.0158 & -1.399 & 0.0429 \\
\hline 2011-new symptomatic grapevines & 1.396 & 0.0427 & -1.25 & 0.1197 & & & & \\
\hline 2012-new symptomatic grapevines & & & & & 1.829 & 0.0023 & -2.124 & 0.0005 \\
\hline H. obsoletus captured specimens & 0.865 & 0.6239 & -0.855 & 0.7179 & 1.179 & 0.1849 & -1.472 & 0.0546 \\
\hline H. obsoletus BNp-infected specimens & 0.987 & 0.4615 & -0.948 & 0.5556 & 1.232 & 0.1612 & -1.606 & 0.0261 \\
\hline Amaranthus retroflexus $\mathrm{L}$. & 1.523 & 0.0256 & -1.515 & 0.0342 & 1.565 & 0.025 & -1.794 & 0.0052 \\
\hline Anagallis arvensis $\mathrm{L}$. & 1.14 & 0.1966 & -1.336 & 0.0513 & & & & \\
\hline Chenopodium album L. & 2.569 & $<0.0001$ & -2.554 & $<0.0001$ & 1.892 & 0.0023 & -1.662 & 0.0102 \\
\hline Convolvulus arvensis L. & 1.536 & 0.0171 & -1.573 & 0.0085 & 1.6 & 0.0134 & -1.634 & 0.0109 \\
\hline Equisetum telmateia Ehrh. & 1.951 & $<0.0001$ & -2.3 & $<0.0001$ & & & & \\
\hline Erigeron canadensis L. & 1.377 & 0.0427 & -1.28 & 0.094 & & & & \\
\hline Lactuca serriola L. & 1.455 & 0.0427 & -1.597 & 0.0085 & 1.528 & 0.0317 & -1.456 & 0.0407 \\
\hline Malva sylvetsris $\mathrm{L}$. & 1.347 & 0.1197 & -1.266 & 0.1624 & 1.72 & 0.0153 & -1.439 & 0.0571 \\
\hline Plantago lanceolata $\mathrm{L}$. & & & & & 1.354 & 0.0556 & -1.376 & 0.0496 \\
\hline Plantago major $\mathrm{L}$. & 1.619 & 0.0171 & -1.987 & $<0.0001$ & 1.312 & 0.0798 & -1.373 & 0.0571 \\
\hline Polygonum persicaria $\mathrm{L}$. & 1.122 & 0.2821 & -0.956 & 0.4786 & 1.603 & 0.0159 & -1.532 & 0.022 \\
\hline Portulaca oleracea L. & 1.93 & 0.0085 & -1.797 & 0.0085 & 2.733 & $<0.0001$ & -2.917 & $<0.0001$ \\
\hline Potentilla reptans $\mathrm{L}$. & 2.737 & $<0.0001$ & -2.551 & $<0.0001$ & 2.669 & $<0.0001$ & -2.488 & $<0.0001$ \\
\hline Rumex acetosa $\mathrm{L}$. & 1.267 & 0.1197 & -1.522 & 0.0171 & 1.615 & 0.0117 & -1.914 & 0.0022 \\
\hline Solanum nigrum $\mathrm{L}$. & 0.983 & 0.3504 & -1.086 & 0.2479 & & & & \\
\hline Sonchus oleraceus L. & 2.193 & $<0.0001$ & -2.414 & $<0.0001$ & 1.155 & 0.1793 & -1.251 & 0.1158 \\
\hline Taraxacum officinale (L.) Wiggers & 1.017 & 0.3333 & -1.003 & 0.3504 & 3.134 & $<0.0001$ & -3.203 & $<0.0001$ \\
\hline Trifolium repens $\mathrm{L}$. & 1.449 & $<0.0001$ & -1.707 & $<0.0001$ & 1.531 & 0.0191 & -1.681 & 0.0087 \\
\hline Urtica dioica $\mathrm{L}$. & 3.025 & $<0.0001$ & -2.753 & $<0.0001$ & 2.369 & $<0.0001$ & -2.288 & $<0.0001$ \\
\hline Veronica arvensis $\mathrm{L}$. & & & & & 1.333 & 0.0724 & -1.34 & 0.0727 \\
\hline Veronica persica Poir. & 1.14 & 0.2137 & -1.199 & 0.1453 & 2.091 & 0.0008 & -2.272 & 0.0003 \\
\hline
\end{tabular}


Table 5 Average indexes of clustering into patch (mean $\mathrm{v}_{\mathrm{i}}$ ) and into gap (mean $\mathrm{v}_{\mathrm{j}}$ ) with associated probability (P) from randomization test in San Pietro di Lavagno vineyard

\begin{tabular}{|c|c|c|c|c|c|c|c|c|}
\hline \multirow[t]{2}{*}{ Folder } & \multicolumn{4}{|c|}{2010} & \multicolumn{4}{|c|}{2011} \\
\hline & mean $v_{i}$ & $P\left(\right.$ mean $\left.v_{i}\right)$ & $\mathbf{P}\left(\right.$ mean $\left.\mathbf{v}_{\mathbf{j}}\right)$ & mean $\mathbf{v}_{\mathbf{j}}$ & mean $v_{i}$ & $P\left(\right.$ mean $\left.v_{i}\right)$ & $\operatorname{mean} \mathbf{v}_{\mathbf{j}}$ & $P\left(\right.$ mean $\left.\mathbf{v}_{j}\right)$ \\
\hline Overall symptomatic grapevines & 0.895 & 0.5849 & -0.898 & 0.5785 & 1.266 & 0.1309 & -1.109 & 0.2554 \\
\hline 2011-new symptomatic grapevines & 1.662 & 0.0426 & -1.52 & 0.0689 & & & & \\
\hline 2012-new symptomatic grapevines & & & & & 1.607 & 0.0335 & -1.652 & 0.0308 \\
\hline H. obsoletus captured specimens & 1.334 & 1.1218 & -1.555 & 0.0568 & 1.115 & 0.2656 & -1.556 & 0.0516 \\
\hline H. obsoletus $\mathrm{BNp}$-infected specimens & 1.561 & 0.0545 & -1.916 & 0.0173 & 0.99 & 0.3945 & -1.145 & 0.2609 \\
\hline Amaranthus retroflexus $\mathrm{L}$. & 2.896 & $<0.0001$ & -2.837 & $<0.0001$ & 3.629 & $<0.0001$ & -3.947 & $<0.0001$ \\
\hline Artemisia vulgaris $\mathrm{L}$. & 3.738 & $<0.0001$ & -3.259 & $<0.0001$ & 3.876 & $<0.0001$ & -3.358 & $<0.0001$ \\
\hline Chenopodium album $\mathrm{L}$. & 2.451 & 0.0005 & -2.548 & 0.0002 & 1.915 & 0.0140 & -1.967 & 0.0099 \\
\hline Convolvulus arvensis L. & 4.678 & $<0.0001$ & -4.772 & $<0.0001$ & 3.194 & $<0.0001$ & -3.061 & 0.0003 \\
\hline Erigeron canadensis $\mathrm{L}$. & & & & & 1.945 & 0.0106 & -2.156 & 0.0034 \\
\hline Malva sylvetsris $\mathrm{L}$. & 2.542 & 0.001 & -2.709 & 0.0005 & 1.966 & 0.0109 & -2.182 & 0.0031 \\
\hline Matricaria chamomilla $\mathrm{L}$. & & & & & 1.592 & 0.0564 & -1.502 & 0.0742 \\
\hline Plantago lanceolata $\mathrm{L}$. & 0.941 & 0.4694 & -1.016 & 0.3712 & 2.049 & 0.0048 & -2.303 & 0.0024 \\
\hline Polygonum persicaria L. & 1.602 & 0.0396 & -1.588 & 0.0389 & 1.849 & 0.0137 & -1.585 & 0.0386 \\
\hline Portulaca oleracea $\mathrm{L}$. & & & & & 3.209 & 0.0003 & -2.347 & 0.0007 \\
\hline Potentilla reptans $\mathrm{L}$. & 3.424 & $<0.0001$ & -3.45 & $<0.0001$ & 3.353 & $<0.0001$ & -3.066 & $<0.0001$ \\
\hline Rumex acetosa $\mathrm{L}$. & 1.081 & 0.2886 & -1.268 & 0.148 & 2.106 & 0.0041 & -2.148 & 0.0024 \\
\hline Sonchus oleraceus L. & 1.912 & 0.007 & -1.826 & 0.0124 & 1.996 & 0.0051 & -2.183 & 0.0014 \\
\hline Taraxacum officinale (L.) Wiggers & 2.839 & $<0.0001$ & -3.186 & $<0.0001$ & 1.422 & 0.0752 & -1.437 & 0.0694 \\
\hline Trifolium pratense $\mathrm{L}$. & 1.995 & 0.006 & -2.393 & 0.0008 & 3.003 & $<0.0001$ & -3.342 & $<0.0001$ \\
\hline Urtica dioica $\mathrm{L}$. & 1.6 & 0.053 & -2.084 & 0.0022 & 0.837 & 0.6338 & -0.896 & 0.5309 \\
\hline
\end{tabular}

Numbers in bold indicate significant results at randomization test $(\alpha=0.05)$. 
1 Table 6 Probability associated to spatial association index in Ronco all'Adige

\begin{tabular}{|c|c|c|c|c|c|c|c|c|}
\hline \multirow[t]{2}{*}{ Folder } & \multicolumn{4}{|c|}{2010} & \multicolumn{4}{|c|}{2011} \\
\hline & $\begin{array}{c}\text { Overall } \\
\text { symptomatic } \\
\text { grapevines }\end{array}$ & $\begin{array}{c}\text { H. obsoletus } \\
\text { captured }\end{array}$ & $\begin{array}{l}\text { H. obsoletus } \\
\text { BNp-infected }\end{array}$ & $\begin{array}{c}\text { 2011-new } \\
\text { symptomatic } \\
\text { grapevines }\end{array}$ & $\begin{array}{c}\text { Overall } \\
\text { symptomatic } \\
\text { grapevines }\end{array}$ & $\begin{array}{c}\text { H. obsoletus } \\
\text { captured }\end{array}$ & $\begin{array}{l}\text { H. obsoletus } \\
\text { BNp-infected }\end{array}$ & $\begin{array}{c}\text { 2012-new } \\
\text { symptomatic } \\
\text { grapevines }\end{array}$ \\
\hline Overall symptomatic grapevines & & 0.6401 & 0.5775 & 0.1942 & & 0.7541 & 0.7611 & 0.8027 \\
\hline 2011-new symptomatic grapevines & 0.1942 & 0.5564 & 0.4097 & & & & & \\
\hline 2012-new symptomatic grapevines & & & & & 0.8027 & 0.4268 & 0.4056 & \\
\hline H. obsoletus captured & 0.6401 & & 0.1501 & 0.5564 & 0.7541 & & 0.0191 & 0.4268 \\
\hline H. obsoletus $\mathrm{BNp}$-infected & 0.5775 & 0.1501 & & 0.4097 & 0.7611 & 0.0191 & & 0.4056 \\
\hline Amaranthus retroflexus L. & 0.3897 & 0.2903 & 0.3327 & 0.518 & 0.8325 & 0.1202 & 0.2291 & $<0.0001$ \\
\hline Anagallis arvensis $\mathrm{L}$. & 0.2862 & 0.4383 & 0.2787 & 0.7697 & & & & \\
\hline Chenopodium album $\mathrm{L}$. & 0.9742 & 0.4143 & 0.1207 & 0.6805 & 0.4824 & 0.5008 & 0.4047 & 0,0811 \\
\hline Convolvulus arvensis $\mathrm{L}$. & 0.0847 & 0.5634 & 0.5221 & 0.6691 & 0.4533 & 0.7645 & 0.6426 & 0,8885 \\
\hline Equisetum telmateia Ehrh. & 0.008 & 0.9263 & 0.9711 & 0.8212 & & & & \\
\hline Erigeron canadensis L. & 0.9511 & 0.91 & 0.9646 & 0.8078 & & & & \\
\hline Lactuca serriola L. & 0.9957 & 0.4038 & 0.4314 & 0.1163 & 0.8749 & 0.4701 & 0.2939 & 0,0831 \\
\hline Malva sylvetsris L. & 0.998 & 0.1943 & 0.0739 & 0.5877 & 0.8749 & 0.088 & 0.1042 & 0,001 \\
\hline Plantago lanceolata $\mathrm{L}$. & & & & & 0.8746 & 0.5043 & 0.5291 & 0,4037 \\
\hline Plantago major $\mathrm{L}$. & 0.6315 & 0.8389 & 0.7605 & 0.8658 & 0.3603 & 0.5163 & 0.335 & 0,4526 \\
\hline Polygonum persicaria $\mathrm{L}$. & 0.0047 & 0.9799 & 0.9188 & 0.8749 & 0.0745 & 0.6729 & 0.6004 & 0,9169 \\
\hline Portulaca oleracea L. & 0.9757 & 0.0184 & 0.0131 & 0.2784 & 0.7083 & 0.0715 & 0.0465 & 0,0372 \\
\hline Potentilla reptans $\mathrm{L}$. & 0.0012 & 0.6658 & 0.6744 & 0.9813 & 0.0106 & 0.9402 & 0.8843 & 0,9996 \\
\hline Rumex acetosa $\mathrm{L}$. & 0.0174 & 0.6679 & 0.599 & 0.9371 & 0.743 & 0.6527 & 0.4487 & 0,3331 \\
\hline Solanum nigrum L. & 0.9707 & 0.3676 & 0.3414 & 0.7219 & & & & \\
\hline Sonchus oleraceus L. & 0.9416 & 0.5846 & 0.2721 & 0.9829 & 0.4714 & 0.86 & 0.5956 & 0,9231 \\
\hline Taraxacum officinale (L.) Wiggers & 0.7748 & 0.7441 & 0.8346 & 0.201 & 0.2866 & 0.9031 & 0.766 & 0,3626 \\
\hline Trifolium repens $\mathrm{L}$. & 0.1644 & 0.7968 & 0.7713 & 0.9225 & 0.7039 & 0.4868 & 0.1575 & 0,8127 \\
\hline Urtica dioica $\mathrm{L}$. & 0.0162 & 0.9377 & 0.9449 & 0.7177 & 0.002 & 0.6903 & 0.422 & 0,8992 \\
\hline Veronica arvensis $\mathrm{L}$. & & & & & 0.7394 & 0.7673 & 0.8207 & 0,8977 \\
\hline Veronica persica Poir. & 0.0294 & 0.6696 & 0.6346 & 0.0216 & 0.8716 & 0.1074 & 0.0287 & $<0.0001$ \\
\hline
\end{tabular}


1 Table 7 Probability associated to spatial association index in San Pietro di Lavagno

\begin{tabular}{|c|c|c|c|c|c|c|c|c|}
\hline \multirow[t]{2}{*}{ Folder } & \multicolumn{4}{|c|}{2010} & \multicolumn{4}{|c|}{2011} \\
\hline & $\begin{array}{c}\text { Overall } \\
\text { symptomatic } \\
\text { grapevines }\end{array}$ & $\begin{array}{c}\text { H. obsoletus } \\
\text { captured }\end{array}$ & $\begin{array}{l}\text { H. obsoletus } \\
\text { BNp-infected }\end{array}$ & $\begin{array}{c}\text { 2011-new } \\
\text { symptomatic } \\
\text { grapevines }\end{array}$ & $\begin{array}{c}\text { Overall } \\
\text { symptomatic } \\
\text { grapevines } \\
\end{array}$ & $\begin{array}{c}\text { H. obsoletus } \\
\text { captured }\end{array}$ & $\begin{array}{l}\text { H. obsoletus } \\
\text { BNp-infected }\end{array}$ & $\begin{array}{c}\text { 2012-new } \\
\text { symptomatic } \\
\text { grapevines }\end{array}$ \\
\hline Overall symptomatic grapevines & & 0.0253 & 0.1509 & 0.0532 & & 0.8921 & 0.8129 & 0.3267 \\
\hline 2011-new symptomatic grapevines & 0.0532 & 0.5309 & 0.0089 & & & & & \\
\hline 2012-new symptomatic grapevines & & & & & 0.3267 & 0.9873 & 0.2799 & \\
\hline H. obsoletus captured & 0.0253 & & 0.0039 & 0.5309 & 0.8921 & & 0.2088 & 0.9873 \\
\hline H. obsoletus $\mathrm{BNp}$-infected & 0.1509 & 0.0039 & & 0.0089 & 0.8129 & 0.2088 & & 0.2799 \\
\hline Amaranthus retroflexus L. & 0.0047 & 0.0073 & 0.0384 & 0.0864 & 0.0265 & 0.1881 & 0.4358 & 0.9227 \\
\hline Artemisia vulgaris $\mathrm{L}$. & 0.7129 & 0.9966 & 0.9886 & 0.5444 & 0.0267 & 0.8550 & 0.5493 & 0.9999 \\
\hline Chenopodium album $\mathrm{L}$. & 0.3711 & 0.0345 & 0.0207 & 0.2801 & 0.9923 & 0.0355 & 0.1494 & $<0.0001$ \\
\hline Convolvulus arvensis L. & 0.0059 & 0.0181 & 0.1076 & 0.06 & 0.0003 & 0.3112 & 0.5864 & 0.9982 \\
\hline Erigeron canadensis L. & & & & & 0.7963 & 0.1749 & 0.2215 & 0.0008 \\
\hline Malva sylvetsris $\mathrm{L}$. & 0.4424 & 0.0115 & 0.1074 & 0.8251 & 0.8697 & 0.6083 & 0.3721 & 0.0001 \\
\hline Matricaria chamomilla $\mathrm{L}$. & & & & & 0.9050 & 0.4645 & 0.4883 & $<0.0001$ \\
\hline Plantago lanceolata $\mathrm{L}$. & 0.0069 & 0.3693 & 0.5637 & 0.0686 & 0.0438 & 0.7471 & 0.3126 & 0.474 \\
\hline Polygonum persicaria $\mathrm{L}$. & 0.4543 & 0.5912 & 0.4954 & 0.2222 & 0.0345 & 0.7619 & 0.6205 & 0.9908 \\
\hline Portulaca oleracea L. & & & & & 0.2708 & 0.7856 & 0.4129 & 0.9987 \\
\hline Potentilla reptans $\mathrm{L}$. & 0.0249 & $<0.0001$ & 0.0019 & 0.056 & 0.2698 & 0.2005 & 0.1682 & 0.4638 \\
\hline Rumex acetosa $\mathrm{L}$. & 0.1342 & 0.005 & 0.0589 & 0.5948 & 0.1095 & 0.7102 & 0.7122 & 0.985 \\
\hline Sonchus oleraceus L. & 0.7761 & 0.5371 & 0.6566 & 0.9523 & 0.0584 & 0.23 & 0.7063 & 0.9968 \\
\hline Taraxacum officinale (L.) Wiggers & 0.2829 & 0.0588 & 0.1947 & 0.3201 & 0.0074 & 0.5029 & 0.3761 & 0.9999 \\
\hline Trifolium pratense $\mathrm{L}$. & 0.5931 & 0.5459 & 0.911 & 0.9145 & 0.0154 & 0.7828 & 0.9968 & 0.5923 \\
\hline Urtica dioica $\mathrm{L}$. & 0.0122 & 0.0272 & 0.0071 & 0.0059 & 0.7016 & 0.3824 & 0.3912 & 0.9756 \\
\hline
\end{tabular}

Numbers in bold indicate associations $(\mathrm{P}<0.025)$, while numbers in italics indicate dissociations $(\mathrm{P}>0.975)(38)$. 
Mori et al., Annals of Applied Biology

\section{FIGURE LEGENDS}

2 Figure 1. Map of counts and clustering indexes of Urtica dioica (A), BNp-infected Hyalesthes

3 obsoletus (B) and new symptomatic grapevines (C) in San Pietro di Lavagno in 2010. The maps

4 show an example of statistically significant association of a weed ( $U$. dioica) of epidemiological

5 group 1 with grapevines and insect vector. Dots represent number of plants or insects observed in

6 each plot. Gridded areas represent patches with interpolated cluster index $v_{i}>1.5$. Vertically lined

7 areas are gaps with interpolated cluster index $\mathrm{v}_{\mathrm{j}}<-1.5$. Values on axis indicate coordinates in

8 meters.

9

10 Figure 2. Map of counts and clustering indexes of Trifolium repens (A), new symptomatic 11 grapevines (B) and BNp-infected Hyalesthes obsoletus (C) in Ronco all'Adige in 2010. The maps 12 show an example of the distribution of a weed ( $T$. repens) of epidemiological group 4 in 13 comparison with grapevines and insect vector. Dots represent number of plants or insects observed 14 in each plot. Gridded areas represent patches with interpolated cluster index $v_{i}>1.5$. Vertically 15 lined areas are gaps with interpolated cluster index $v_{j}<-1.5$. Values on axis indicate coordinates in 16 meters. 
1

2

3

4

5

6

7

8

9

10

11

12

13

14

15

16

17

18

19

20

21

22

23

24

25

26

27

28

29

30

31

32

33

34

35

36

37

38

39

40

41

42

43

44

45

46

47

48

49

50

51

52

53

54

55

56

57

58

59

60
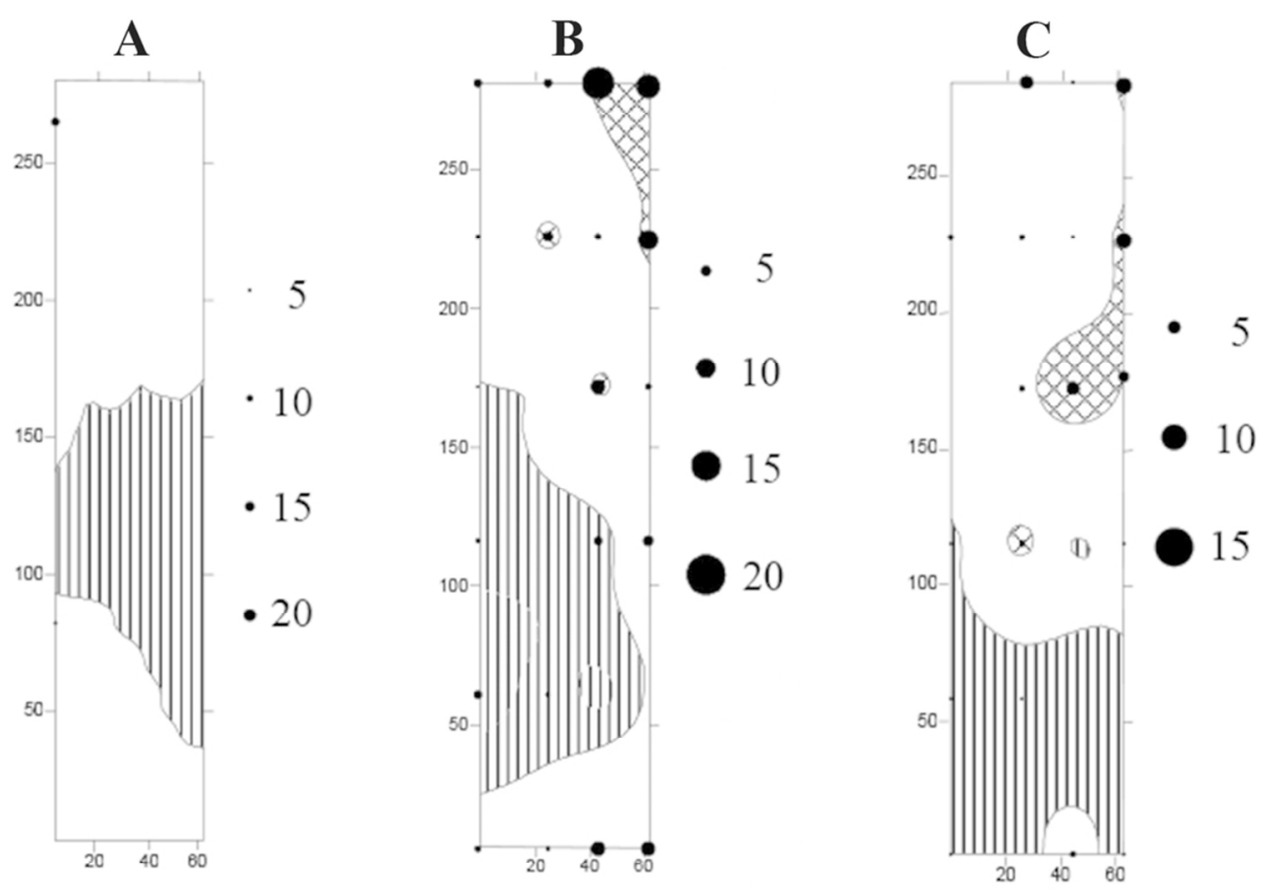

\section{Figure 1}

Map of counts and clustering indexes of Urtica dioica (A), BNp-infected Hyalesthes obsoletus (B), and new symptomatic grapevines (C) in San Pietro di Lavagno in 2010. The maps show the statistically significant associated distributions of Urtica dioica (epidemiological group 1), grapevines and insect vector. Dots represent number of plants or insects observed in each plot. Gridded areas represent patches with interpolated cluster index $v_{i}>1.5$. Vertically lined areas are gaps with interpolated cluster index $v_{j}<-1.5$. Values on axis indicate coordinates in meters.

$91 \times 79 \mathrm{~mm}(300 \times 300 \mathrm{DPI})$ 
A

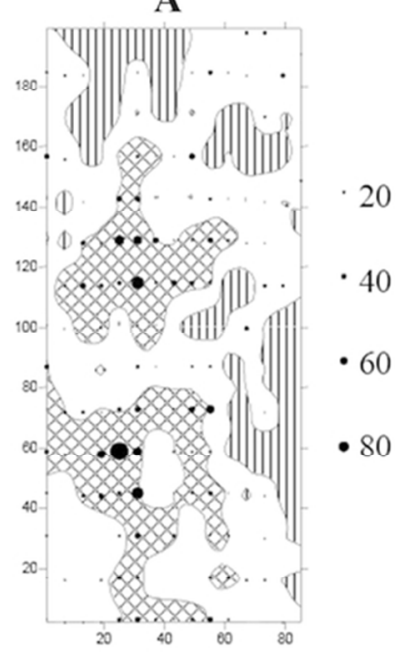

B

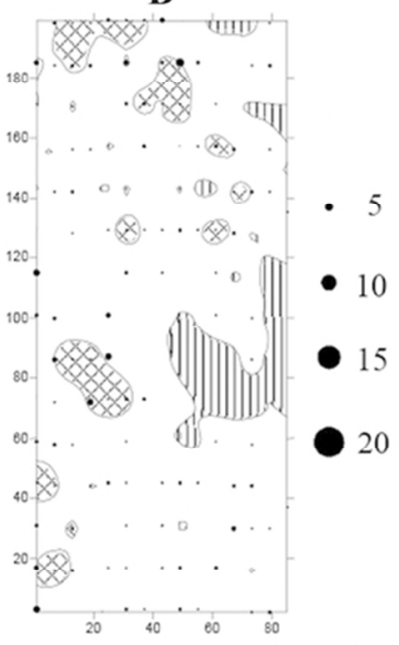

C

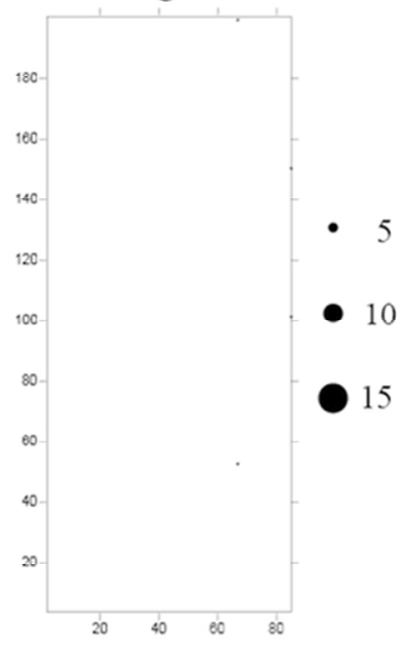

\section{Figure 2}

Map of counts and clustering indexes of Trifolium repens (A), BNp-infected Hyalesthes obsoletus (B), and new symptomatic grapevines (C) in Ronco all'Adige in 2010. The maps show the distributions of Trifolium repens (epidemiological group 4), grapevines and insect vector. Dots represent number of plants or insects observed in each plot. Gridded areas represent patches with interpolated cluster index $v_{i}>1.5$. Vertically lined areas are gaps with interpolated cluster index $v_{j}<-1.5$. Values on axis indicate coordinates in meters. 